\title{
The Study on Project Information Management System for the Efficient Project Management of Commercialization-Linked Technology Development
}

\author{
Chang-Su Kim, Bong-Im Jang, Member, KIMICS
}

\begin{abstract}
As researches of on scientific technology are considered as a pivotal factor of a national competitiveness, the central and local governments have extended assistance for commercialization-linked technology development (CLTD) and accordingly various outputs are coming out now. However, the valuable findings from painstaking researches are not sufficiently distributed to or shared with other governmental and public organizations, and businesses. As a result, it could be possible for them to become unknown and unused. Therefore, it is being sensed that a measure to coordinately and systematically manage the information and outputs derived from the research projects is urgently needed. Hence, this study designs PIMS to manage CLTD efficiently and transparently.
\end{abstract}

Index Terms-CLTD, NTIS, PIMS, Project Management, R\&D Information System.

\section{I.INTRODUCTION}

SUCH technologies appeared in the late 20th century as Nano Technology (NT), Information Technology (IT), Bio Technology (BT), and Mechatronics Technology (MT) are receiving continuous supports and as a result diverse research outputs are coming out. However, those researches are conducted by companies or research institutes at an unsystematically planned manner, so that the outcomes are not well circulated to other governmental or business organizations. Therefore, many of them are buried the underground.

Also, current researches are asked to not only limit themselves to a certain area with depth but converges many fields and technologies into a new form. Therefore, the government-aided research projects are expected to bring in multifaceted knowledge and findings more than ever.

Although it could be varied by surrounding environments, $R \& D$ projects can find its significance only when it can accomplish at least three objectives more efficiently than a civic organization: complementing the inefficiency of market-leading technological innovation,

Manuscript received July 12, 2011; revised July 14, 2011; accepted July 25, 2011

Chang-Su Kim is with the Business Support Division, Daejeon Technopark, Daejeon, 305-510, Korea (Email: ddoja@djtp.or.kr)

Bong-Im Jang(Corresponding Author) is with the Department of Multimedia Engineering, Hannam University, Daejeon, 306-791, Korea (Email: jangg11@nate.com) reducing the uncertainty during the process of technological innovation, and securing the national competitiveness for a national system of technological innovation. Therefore, a government authority to promote and handle national $\mathrm{R} \& \mathrm{D}$ projects should play triple roles in the process: as R\&D fund sponsor, generator of a new technology, and a market regulator.

To do so, the authority needs to establish a proper basic foundation on which research outputs of various fields can be converged. That is, the system should be introduced that helps the outcomes be applied and distributed well. As the first step to that goal, most urgently, there must be the system that systematically integrates and manages the information of research tasks and outputs derived from the research projects carried by every each company and research institute.

The business support process for Computerization and the efficiency of business support services is necessary to implement. Support for businesses performance management and business support for industry-friendly business process management and automation management system is required.

Therefore, it is being sensed that a measure to coordinately and systematically manage the information and outputs derived from the research projects is urgently needed. Hence, this study designs PIMS to manage CLTD efficiently and transparently.

In the first chapter, this study explains Project Information Management System (PIMS) which was developed to help to establish the kind of integrated system. And it discusses about a national $R \& D$ management system in the second chapter and the major components of the system in the third chapter of this study.

\section{RELATED STUDIES}

This chapter looks into the needs of PIMS and compares the current status of domestic and overseas R\&D information systems.

\subsection{The Needs of PIMS}

The government legislated 'Act of Performance Evaluation and Management for National Research and Development Projects in 2005 in an attempt to enhance the efficiency of the investment in $R \& D$ projects at the governmental level. 
On the basis of this act, the first 'Preliminary Plan for Management and Utilization of Research Outputs' was introduced in 2006[1,2]. The figure 1 shows the 8 initiatives in 3 sectors.

As the first plan ended in 2010, the second plan is in preparation for the next 5 year's management and utilization of research performance [3]. This reflects that a systematic performance management is more and more needed for national $R \& D$ projects.

It has been suggested that the government and public organizations have common problems in managing $\mathrm{R} \& \mathrm{D}$ projects: lack of integrated performance management system, subsequent supporting system, and standardized system for information distribution [4,5]. Therefore, PIMS is needed to systematically manage and diffuse the outputs of CLTD.

\begin{tabular}{|c|c|c|}
\hline $\begin{array}{l}\text { Management of } \\
\text { research performance }\end{array}$ & $\begin{array}{l}\text { Utilization of research } \\
\text { performance }\end{array}$ & $\begin{array}{l}\text { Expansion of } \\
\text { infrastructure }\end{array}$ \\
\hline $\begin{array}{l}\text { - preparing } \\
\text { guidelines for } \\
\text { managing research } \\
\text { performance } \\
\text { - system } \\
\text { establishment for } \\
\text { collecting and } \\
\text { distributing of } \\
\text { research } \\
\text { performance } \\
\text { - Construction of } \\
\text { management } \\
\text { system for research } \\
\text { performance }\end{array}$ & $\begin{array}{l}\text { - planning of } \\
\text { utilization-oriented } \\
\text { R\&D and } \\
\text { establishingthe } \\
\text { management } \\
\text { mechanism } \\
\text { - Support for co- } \\
\text { utilization and } \\
\text { commercialization of } \\
\text { research performance } \\
\text { - inspection of } \\
\text { utilization advantage } \\
\text { of research } \\
\text { performance and } \\
\text { construction of reflux } \\
\text { system }\end{array}$ & $\begin{array}{l}\text { - Expert training for } \\
\text { management and } \\
\text { utilization of } \\
\text { research } \\
\text { performance } \\
\text { - System } \\
\text { Improvement for } \\
\text { management and } \\
\text { utilization of } \\
\text { research } \\
\text { performance }\end{array}$ \\
\hline
\end{tabular}

Fig. 1. Preliminary Plan for Management and Utilization of Research Outputs

\subsection{The Current Status of Domestic R\&D Information System}

National Science \& Technology Information Service (NTIS) is the representative example of the Korean R\&D information systems run at a governmental level. This NTIS is a knowledge portal to assist national R\&D project information and was established to improve the efficiency in the entire process of $R \& D$ projects from planning to application stage of $R \& D$ outputs.

It has the objective of providing the information (tasks, human resources, equipment, performance output, and so forth) which is related to R\&D projects run by the government. It is linked to 15 ministries and offices (Representative Research Management Specialist Group) handling the national $R \& D$ projects [4-8].

Besides NTIS, basic technology research information networks provide necessary information of the progression status, assessment of the outputs of sponsored research projects through assessment reports. Also, there is nongovernmental research project management system that provides the services of utilizing the outputs of research projects by associating the outcomes to a performance management system.

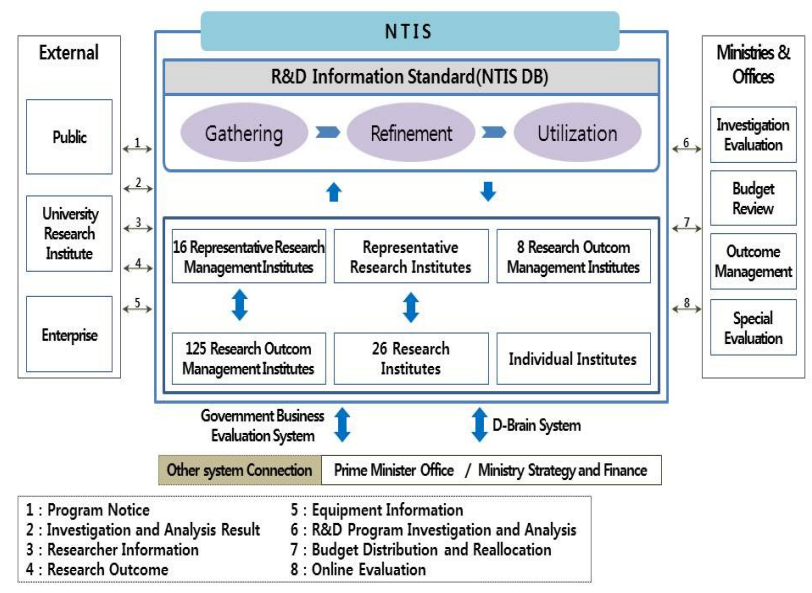

Fig. 2. Concept of NTIS

In addition, many studies [9-11] have been conducted on $R \& D$ performance management system for an individual project. However, the study for the establishment of PIMS for CLTD is still insufficient. Accordingly, this study suggests PIMS for CLTD in an attempt to enhance a systematic management and efficient distribution of information and outputs of R\&D projects carried by civic enterprises and research institutes.

\section{PROJECT INFORMATION MANAGEMENT SYSTEM}

PIMS is the information system to assist the whole process of a project from the selection of research tasks to the follow-ups. Thus it provides a standardized way of planning a research project, choosing a research objective, managing project progression, evaluating the outputs, and applying and utilizing them.

\subsection{System Configuration}

As shown in the below Figure 3, PIMS consists of 3 major systems of user management, information gathering, and information service. User management system has a module of registering and modifying user information, a module of managing the user authorization by user group and function, and user verification module.

In the information gathering system, user can register and modify research information, performances (thesis, seminar, technology transfer, intellectual property), and organization's specific information (organization information, budget status, and human resources) through a web-input interface. 


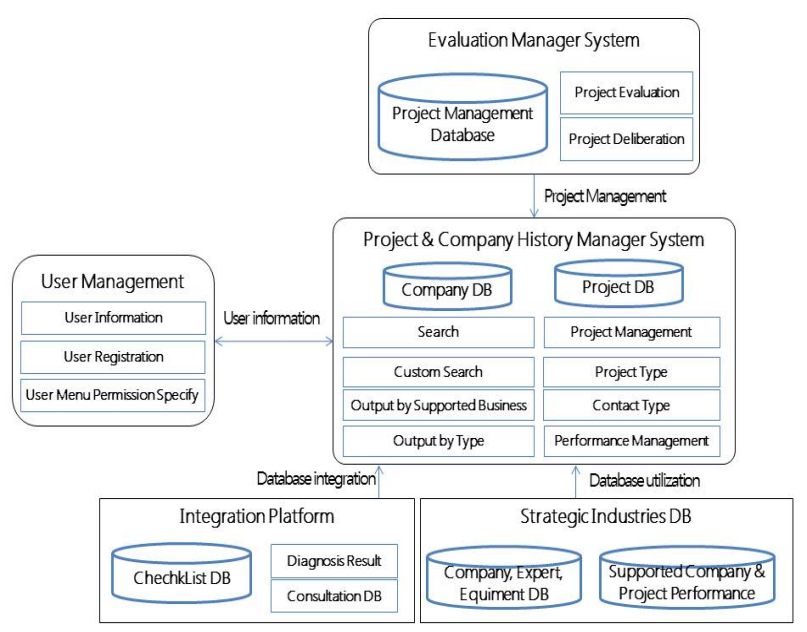

Fig. 3. PIMS System Configuration

The module of information service provides a reading (=viewing) service of project tasks and objectives by sponsored organization and project, an integrate searching service by keyword, assessment support service allowing original assessment data by organization to be viewed, and statistical services of data and graphic charts.

\subsubsection{Database Configuration}

The data gathered in the information collection system can be realized in ER Diagram as shown in Figure 4. The names of sponsoring organizations and their codes in "Organization Code" can be referred by year and saved in the database.

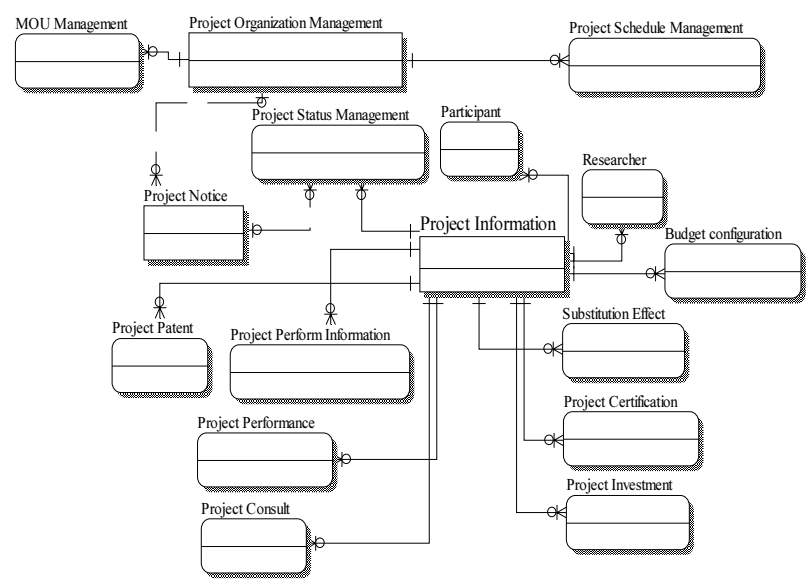

Fig. 4. E-R Diagram

Because each organization can carry out multiple projects and thus multiple research outputs such as thesis, seminar, intellectual property or technology transfer can exist, 1 to $\mathrm{N}$ ( 0 or more) relation is interlinked as shown in Figure 4. Also, the specific information (mission, structure, and so on) of each organization, its budget status, human resources, research equipment and facilities, composition of a research budget by fund source, and royalty imposition status can be inquired and saved in the database. As for the status of research machines, equipment, and facilities among the above, information about them is in control by each research institute, so that they should be input first. Accordingly, 1 to $\mathrm{N}$ ( 0 or more) relation exists for organization code.

As for user information, organization code is referred for the purpose of the classification of user's organization. Therefore, user authorization should be controlled by user group.

\subsection{Data Gathering}

Date collection system consists of the modules of a web input interface, list data upload, and automatic link to other systems.

\subsubsection{Web Input Interface}

Web input interface provide the functions of input, modification, and referral for all the data in ER Diagram shown above. User is first authorized to a user group in which he/she belongs and to use the system to input data within the authorized areas to him.

\subsubsection{List Data Upload}

List data upload module is designed to facilitate individual researchers or supervisor for a project to upload research data and performance information of each research organization in this system. As a research institute has its own and a project management system for research tasks and performance information, this system helps it to retrieve the data and upload in PIMS system in batch. Information manager in each research institute converts the data of research objectives and performance, which exist in his/her own organization database system, to the excel format required according to PIMS system. And then he/she uses the list data upload module to upload them to PIMS system. The data are processed in batch. Partial management of the uploaded data in batch can be processed by a web interface.

The interoperable module with other systems provides a way to integrate the performance information of many different formats outside the concerned organizations.

\subsubsection{Automatic Association with Other systems}

3.2.1 and 3.2.2 show complementary methods of data gathering before the competition of automated association module. The optimal goal of data collection is an automatic interlinking with other systems. This chapter suggests the draft for the association, which is one step before automatic association with other systems

When data need renewing, the interlink-support client of the basic technology research information network is put into operation to collect $\mathrm{R} \& \mathrm{D}$ performance information of a concerned organization by interaction of the interoperability-supporting server of the organization. In this process, VIEW is used to mediate two different formats of R\&D performance information. View can be 
operated in format of table and excel. Currently table or excel are being used simply for interlinking $R \& D$ performance information in DB structure. But afterwards, XML catalogue format with structural information will be employed. In addition, security will be reinforced by codification system for data in transit among interoperability support module.

\subsection{Information Service}

Information service provides the modules of viewing, searching, assessment-support and statistical viewing service for project tasks and performance information. Each system will be explained below.

\subsubsection{Viewing Project Tasks and Performance Information}

As shown in Figure 5, user can read the project tasks and performance information by organization through a web interface. Also, he/she can inquire project outputs related to specific research tasks or conversely retrieve research tasks that generate research outputs such as thesis or seminar. By these functional services, user can have easier access to research project outputs than ever.

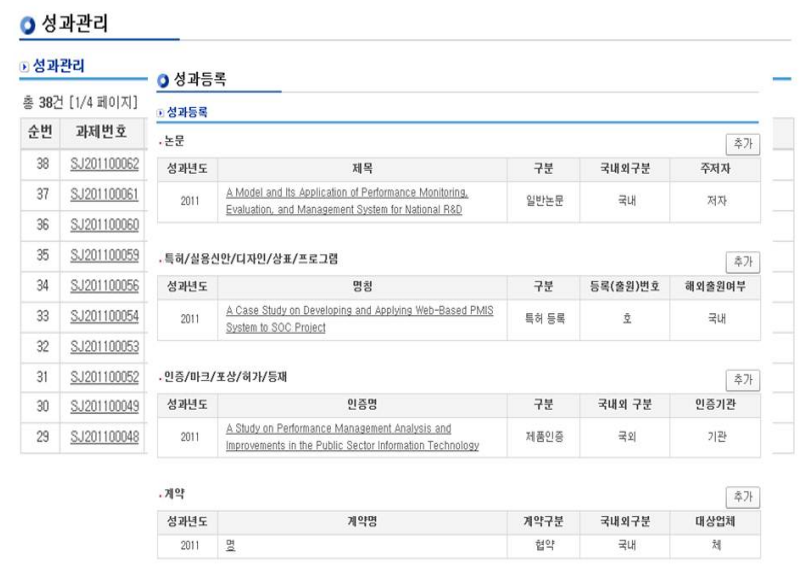

Fig. 5. Viewing Performance Information

\subsubsection{Assessment Support and Statistics Viewing}

The whole volume of original assessment reports is provided for assessment viewing or assessment support in these modules.

User can obtain various statistical information as well as basic information when he/she wants to use them to assess the project of an organization. As shown in Figure 6 , user uses the interface to compare research performances by stage and organization. Also this module makes it possible to refer the trend of research outputs in number by year. The organization-unique information and a variety of statistical information can be used as objective base for the government or public organizations to promote and determine $R \& D$ projects and its support policy at the governmental level.
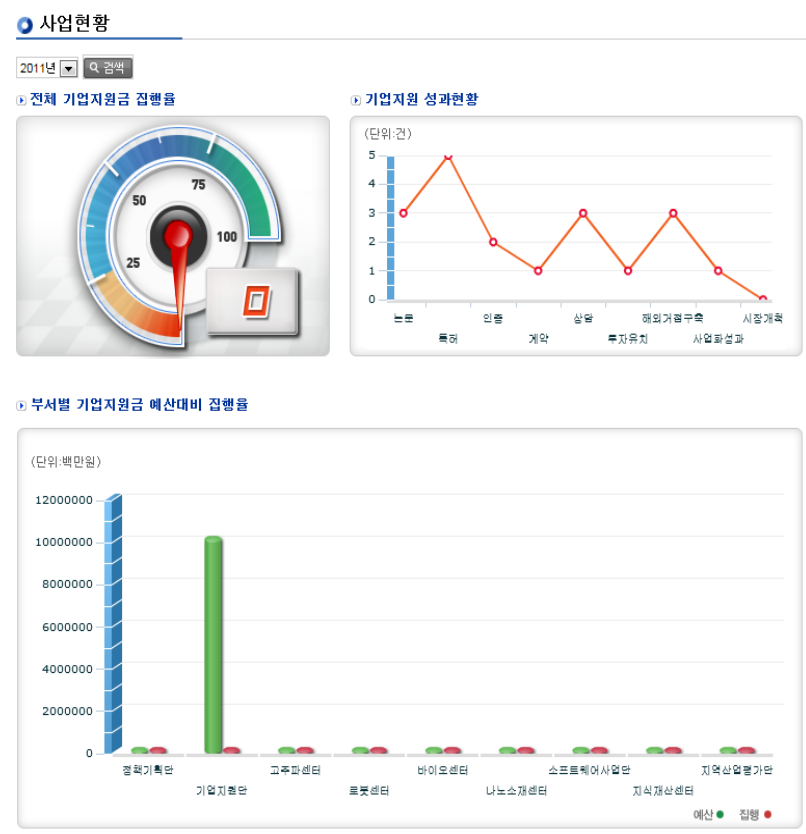

Fig. 6. Statistics Viewing

\section{CONCLUSIONS}

Project information is information of the outputs derived in the process of carrying a research project. PIMS defines it as project plan, announcement, selection, implementation, assessment management, and follow-up. So far, the central or local government project operators have shown such problems as low research productivity, lower rate of practicalization than that of task fulfillment, lack in connectability of research outputs to commercialization, target management system, project management information system, and so on.

PIMS has its importance in systematically collecting and managing the basic information and research performance on various project tasks carried by companies or research institutes and in providing searching and inquiring services upon this information, unique or related information about organizations, assessment reports-related graphic and statistical information.

Establishing and providing this system can suggest a guideline for research tasks and performance information carried in different and separate forms by organization. Therefore, it can place a ground for integrate research project performance management. In addition, its convergent environment, in which scattered research performance information is integrated, can make it possible for efficient use of research outputs of each project operator and play the role of a promotion window. And it can provide various statistical data and information combining unique information of project operators with their research outputs, which are helpful in objectively assessing the research outputs of $\mathrm{R} \& \mathrm{D}$ project carried by 
the operators.

It is expected that $R \& D$ industry will be more complicated in future by high-tech convergence. And because the close cooperation among university, business, and research institute will be essential, project information systems of central and local government should be upmost utilized. Also, general improvements and countermeasures can be used as a check list in the supervision of R\&BD information system.

\section{REFERENCES}

[1] M.S.Kim et. al., "A Model and Its Application of Performance Monitoring, Evaluation, and Management System for National R\&D," Journal of Korea Technology Innovation Society, vol.11, no.4, pp.613-638, 2008.

[2] B. M. Kim, "Basic Plan for Promoting the Management and Application,"Health Industry Technology Trend, 2006.

[3] Ministry of Education , Science and Technology, http://www.mest.go.kr/web/1010/ko/board/view.do?bbsId=86\&bo $\operatorname{ardSeq}=19266$

[4] M. G. Hwang, "A Study of Building Foundation for Promoting the Management and Application of Research Performance and Supporting Effective Operation of National R\&D Management Agency," KISTEP, pp.5-9, 2007.

[5] B.J. Ryu et. al., "A Study on the Construction of the National R\& D Knowledge Information -Mainly Focused on the Research Planning and Management," Journal of KLISS, vol.38 no.1, pp.281-301, 2004.

[6] Y.M.Ko, B.T.Kim, "Research performance management and revitalization plan of public research institute," KISTEP Issue Paper, pp.5-9, 2007.

[7] B.J.You, K.S.Choi, "A Study on the Construction of the National R\&D Knowledge Information," Journal of the Korean society for library and information science, vol.38, no1, pp.281-301, 2004.

[8] National Science \& Technology Information Service, http://www.ntis.go.kr

[9] H.K.Park, "A Case Study on Developing and Applying Web-Based PMIS System to SOC Project," Journal of Korean Society of Civil Engineers, vol.25, no.2D, pp.297-304, 2005.

[10] W.K.Joo et. al., "An Integrated R\&D Information Service System of Korea R\&D Information Network," Proceedings of Korea Computer Congress, vol.32, no.1, pp.184-186, 2005.

[11] Y.S.Lee et. al., "A Study on Performance Management Analysis and Improvements in the Public Sector Information Technology," Journal of Korean Association for Regional Information Society, vol.11, no.3, pp.1-30, 2008.

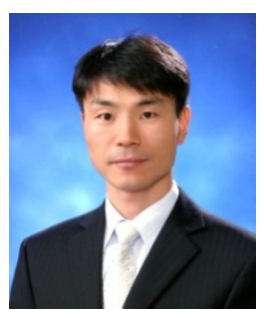

Chang-Su Kim He received the B.S., M.S. and Ph. D. degrees in Computer Engineering from Paichai University, in 1996, 1998 and 2002, respectively. From 2001 to 2004, he has a lecturer of Paichai University, IT Education Center. From 2005 to 2010, he has a Full-time lecture in Department of Internet at Chungwoon University. Since 2011, he has worked as a Manager in Business Support Division at DaejeonTechnopark. His current research interests include Document Information Processing, Web Service, and Mobile Internet Service

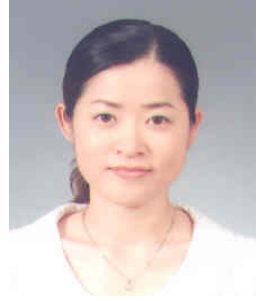

Bong-Im Jang She received the M.S. degree in multimedia engineering from the Hannam University in 2003. She is a Ph.D. degree in multimedia engineering from Hannam University in 2008 and a researcher in the Business Support Division at Daejeon Technopark. Her current research interests includes USN, Sensor Web, Multimedia and Web Service. 